\title{
SABOR, MEIO AMBIENTE E AGRICULTURA FAMILIAR: UM ESTUDO SOBRE A PERCEPÇÃO DOS CONSUMIDORES DO “ABACAXI TERRA DE AREIA" NO RIO GRANDE DO SUL
}

\author{
Taste, Environment and Family Farming: A Study on the Perception of "Terra De Areia Pineapple" \\ Consumers in Rio Grande do Sul, Brazil
}

\begin{abstract}
RESUMO
O cultivo do abacaxi chamado "terra de areia" é desenvolvido em pequenas propriedades no Litoral Norte do Rio Grande do Sul. A região é a maior produtora de abacaxi do estado, com uma área plantada de 245 ha e produção superior a 3 milhões de frutos anuais. Uma das possibilidades de gerar reconhecimento e agregar valor ao abacaxi seria valorizar sua origem. O objetivo deste trabalho é apresentar os resultados de uma pesquisa realizada com consumidores no âmbito de um projeto de pesquisa sobre o potencial para obtenção de uma Indicação Geográfica (IG) para o "abacaxi terra de areia". A coleta de dados foi feita atravéspor meio de um questionário estruturado, a metodologia seguiu o modelo 'survey'. Os resultados mostram que os consumidores julgam a IG de forma positiva, como ferramenta que beneficia produtores e consumidores. As motivações ligadas ao consumo do "abacaxi terra de areia" são sabor, a busca por um alimento saudável e o fato de se tratar de cultura tradicional do Litoral Norte do RS desenvolvida por agricultores familiares, por meio de métodos de produção sustentáveis.
\end{abstract}

Larissa Bueno Ambrosini

Fundação Estadual de Pesquisa Agropecuária

larissabueno@gmail.com

Raquel Paz da Silva

Fundação Estadual de Pesquisa Agropecuária

raquel-silva@fepagro.rs.gov.br

Recebido em: Aprovado em:

Avaliado pelo sistema double blind review

Avaliador científico: Paulo Henrique Montagnana Vicente Leme

DOI: 10.21714/2238-68902017v19n2p109

\begin{abstract}
The pineapple cultivation in the coast of Rio Grande do Sul, in south of Brazil, is developed on small farms. The region is largest producer of pineapple in the department with 245 ha planted and a production of 3 million fruits annually. One of the possibilities to generate recognition and add value to pineapple would revalue its origin. The aim of this paper is to present the results of a survey of consumers in the context of a research project about the potential for achieving a Geographical Indication (GI) for the "terra de areia" pineapple. Data collection was done through a structured questionnaire; the methodology followed the 'survey' model. The results show that consumers judge the GI positively as a tool that benefits producers and consumers. The motivations linked to the consumption of "terra de areia" pineapple are the taste, the search for a healthy food and the fact that it is traditional culture of the Coast of the RS, developed by family farmers through sustainable production methods.
\end{abstract}

Palavras-chave: Indicação geográfica, Certificação, Frutas, Território.

Keywords: Geographical indication, Certification, Fruits, Territory.

\section{INTRODUÇÃO}

A Indicação Geográfica (IG) é um conceito originalmente europeu, que foi desenvolvido na França, a partir do início do século XX, quando uma crise importante da vitivinicultura fez com que fossem criadas regras para o uso de nomes geográficos (BÉRARD; MARCHENAY, 2007). Essa ferramenta de proteção foi se difundindo para outros países europeus e, gradualmente, para países em desenvolvimento.

A IG, como instrumento de política pública, ganhou importância, em âmbito europeu, a partir dos anos 1990, com a consolidação de uma política de desenvolvimento diferenciada da PAC (Política Agrícola Comunitária), pela implementação do Programa LEADER (corresponde à sigla, em francês "Liaisons entre activités de Developement de L'Economie Rural").

A geração de empregos, o incentivo à inovação e resgate de saberes figuram como elementos de destaque no balanço sobre os êxitos das iniciativas Leader. E, é justamente nesse contexto que ganha relevo a estratégia de fortalecimento aos produtos com identidade cultural, como é precisamente o caso das indicações geográficas 
em toda sua riqueza e diversidade, assim como das especialidades regionais (ANJOS et al., 2014, p. 209).

O aumento do interesse em torno da IG está relacionado a uma dinâmica de exploração de nichos de mercado, ligados a marcas de qualidade ou produtos típicos (FAVARETO, 2010). As noções de IG mobilizam relações complexas entre um produto e sua origem, delimitada em termos espaciais e históricos. A análise dessas relações permite a compreensão da formação de um sistema agroalimentar dito tradicional, cujo produto originário desse sistema pode ser analisado como um patrimônio do local (AURIER; FORT; SIRIEIX, 2005; BARJOLLE; BOISSEAUX; DUFOUR, 1998; BÉRARD; MARCHENAY, 2007; VALCESCHINI, 2000).

Ainda, é preciso salientar que o dispositivo é proposto, também, como uma alternativa para viabilizar e desenvolver zonas rurais que ficaram à margem dos processos de modernização agrícola. Pelo fato de terem preservado práticas, produtos e paisagens, a agregação de valor advinda de um reconhecimento como a IG foi proposta como "uma via capaz de resgatar os vínculos com o território e fortalecer a identidade sociocultural dos grupos envolvidos" (ANJOS et al., 2015, p. 210) e que possibilitasse a essa oferta sair da lógica competitiva das commodities e remunerar de forma satisfatória produções que, normalmente, apresentam escala menor.

Por essa inserção diferenciada nos mercados, as IG também são consideradas dispositivos que podem auxiliar na preservação do patrimônio material e imaterial (CERDAN; VITROLLES, 2008; PELLIN; RIBEIRO; MANTOVANELI JÚNIOR, 2016), que podem se tornar "uma alternativa para a proteção de pequenos produtores ameaçados por normas sanitárias cada vez mais rígidas, além de responder a uma crescente demanda dos consumidores por produtos étnicos e sustentáveis" (BELAS; WILKINSON, 2014, p. 59).

No Brasil, segundo Anjos et al. (2014), a concepção que inspira os processos de reconhecimento de IG parece distante daquela que tem inspirado outras experiências internacionais, já que nas iniciativas brasileiras parece predominar a ênfase da lógica setorial (BARBOSA, 2015). No entanto, muitos estudos têm se dedicado a analisar o potencial de transbordamento da IG para alavancar outras atividades no território, notadamente o turismo (ANJOS et al., 2015; BERTONCELLO; SILVA; GODINHO, 2016; DALLABRIDA, 2013; MAIORKI; DALLABRIDA, 2015; VALENTE et al., 2012). Um dos entraves apontados, tanto para efetivação de uma estratégia mais ampla que abarque também o desenvolvimento territorial, quanto para o amadurecimento mesmo das IG já registradas, é a capacidade de melhor articulação entre atores produtivos e institucionais envolvidos (ANJOS et al., 2014; BRANCO et al., 2013; BRANDÃO, 2016; NIEDERLE, 2011; ROCHA, 2016).

Segundo Matos e La Rovere (2017), no entanto, outro problema tem sido a falta de clareza na utilização de alguns conceitos normativos, apesar da legislação brasileira datar de quase $20 \operatorname{anos}^{1}$. As autoras demonstram que há certa falta de alinhamento entre o arcabouço normativo brasileiro com relação ao europeu, especialmente no que se refere ao reconhecimento da dimensão histórica e cultural, e uma ausência de critérios para analisar a importância do fator humano nos processos de reconhecimento de IG no Brasil ${ }^{2}$. Outro problema apontado pelas autoras é que a novidade do tema para as instituições brasileiras envolvidas em processos de fomento a IG leva a diferentes interpretações de alguns conceitos.

A falta de critérios para analisar elementos como saberes tradicionais, inserção histórica e cultural pode ter como consequência a perda gradual de práticas e receitas que fazem parte do patrimônio gastronômico e cultural do país (BELAS; WILKINSON, 2014; BRANCO et al., 2013; SANTOS, 2014). Segundo Santos (2014, p. 9), os instrumentos, como a IG

\section{[...] devem estar em consonância com o ambiente sociocultural em que os produtos estão inseridos. Pensados enquanto patrimônio cultural e como constitutivos de sistemas, nos produtos alimentares tradicionais a dissociação entre material e simbólico pode levar à perda de características essenciais, que conferiram notoriedade aos produtos.}

Nesse contexto, percebemos que para produtores, a IG tem sido vista como um meio de proteger e valorizar sua oferta. Entretanto, trata-se de um sinal endereçado aos consumidores. Alguns estudos brasileiros têm procurado

\footnotetext{
1 "O marco legal das IG do Brasil (Lei 9279 de 14/05/1996) é bastante recente e contempla somente duas figuras de proteção, quais sejam, as Indicações de Procedência (IP) e as Denominações de Origem (DO). A IP se refere ao nome geográfico do país, cidade, região ou localidade de seu território, a qual se tornou conhecida como centro de extração, produção ou fabrico de um determinado produto, ou pela prestação de um determinado serviço. A DO, por seu turno, indica o nome geográfico de um país, cidade, região ou localidade de um território e designa um produto ou serviço cujas qualidades se devem exclusiva ou essencialmente ao meio geográfico, incluindo os fatores naturais e humanos. A distinção entre ambas as figuras está no fato de que, no caso da IP, o relevante é a notoriedade associada à qualidade que alcançou um determinado produto ou serviço, ao passo que no caso da DO a excelência de um ou de outro deve estar ancorada, obrigatoriamente, nos aspectos físicos (solo, água, clima), humanos e culturais do meio onde houve o processo de obtenção ou produção. Tanto a IP quanto da DO devem ter seus respectivos registros no Instituto Nacional de Propriedade Industrial (INPI)" (ANJOS et al., 2015, p. 210).

2 Para uma revisão completa e atual acerca da evolução normativa das IG no Brasil, ver: BARBOSA; DUPIM; PERALTA, 2016; MATOS; LA ROVERE, 2017.
} 
demonstrar uma atitude favorável de consumidores vis$\grave{a}$-vis às indicações de origem. É o caso de um estudo feito sobre a "carne do Pampa" (BRANDÃO, 2009), ou sobre uma possível IG para carne do Mato Grossso do Sul para bovinos de raças locais como "Pantaneiro" e o "Curraleiro Pé-Duro" (MORAES et al., 2013), ou sobre IG em geral, enquanto fator de diferenciação de vinhos (GLASS; CASTRO, 2008). Mas, os resultados se referem mais à aprovação por parte dos consumidores com relação à presença de tal certificação, muito pouco sabemos sobre como os consumidores brasileiros percebem a relação entre IG, produto e território, e mesmo se a IG, enquanto ferramenta para a proteção de saberes e práticas culturais, encontra respaldo junto aos consumidores brasileiros.

Nosso estudo faz parte de um projeto de pesquisa financiado pelo $\mathrm{CNPq}^{3}$ que pretende levantar dados e discutir o potencial do "abacaxi terra de areia" em obter uma $\mathrm{IG}^{4}$. O projeto prevê caracterização das condições ambientais do território (climáticas e de solo, com foco na cultura do abacaxi); a caracterização histórica da ocupação do território (com foco na cultura do abacaxi); a realização do diagnóstico e caracterização dos sistemas produtivos atualmente implementados pelos produtores de abacaxi, verificando sua situação produtiva e econômica; a caracterização da cadeia produtiva e canais de comercialização do "abacaxi terra de areia" e uma pesquisa sobre a percepção dos consumidores com relação ao produto. $\mathrm{O}$ presente trabalho pretende apresentar os resultados desse último objetivo: Pesquisa sobre a percepção dos consumidores com relação ao "abacaxi terra de areia", procurando também investigar seu conhecimento com relação à IG. A contribuição do artigo para o debate brasileiro é discutir a IG, a partir da noção de terroir, verificando a percepção dos consumidores no que concerne às dimensões que o compõem, a saber a dimensão físico-geográfica e a dimensão histórico-cultural.

Para tanto, iniciamos apresentando o contexto de produção do "abacaxi terra de areia" e justificando o estudo acerca do potencial para obtenção de IG. A segunda seção apresenta o referencial teórico mobilizado para a pesquisa com os consumidores, que repousa na proposição de Lancaster sobre

${ }^{3}$ Potencialidades para a obtenção de Indicação Geográfica (IG) por parte do abacaxi (Ananas comosus) de Terra de Areia - RS aprovado no Edital MCTI/CNPq n. 14/2013 - Universal.

${ }^{4} \mathrm{Em}$ nosso projeto não especificamos o tipo de IG que poderão requerer os produtores de abacaxi, se IP ou DO, pois acreditamos que essa definição deverá ser facilitada após a conclusão de todas as etapas do projeto e de acordo com os objetivos e capacidade de articulação dos atores locais. Ainda, a pesquisa sobre os canais de comercialização, em fase de análise, tem nos auxiliado a comprovar a reputação que o produto construiu ao longo do tempo. Entretanto, os dados sobre clima e solo ainda estão em fase de coleta, e podem também auxiliar na compreensão das características do fruto. a demanda por atributos, a partir dos quais os consumidores operam suas escolhas; passando, em seguida, a discutir a IG como um patrimônio local, a partir da noção francesa de terroir e das dimensões que a compõem. As seções subsequentes apresentarão a metodologia utilizada para a coleta dos dados, a discussão dos resultados e as considerações finais.

\subsection{O Cultivo do Abacaxi Terra de Areia no Litoral Norte do Rio Grande do Sul}

O abacaxi (Ananas comosus (L.) Merril) é uma planta pertencente à família Bromeliaceae que apresenta aproximadamente 2700 espécies, herbáceas, epífitas ou terrestres, distribuídas em 56 gêneros, originárias das Américas (CRESTANI et al., 2010). De acordo com Collins (1960), o centro de origem das espécies do gênero Ananas é o Hemisfério Oeste, na América tropical e subtropical, e compreende a área entre as latitudes $15^{\circ}$ Norte e $30^{\circ} \mathrm{Sul}$ e as longitudes $40^{\circ}$ Leste a $75^{\circ}$ Oeste, correspondendo às regiões Sul, Sudeste e Centro-Oeste do Brasil e Norte da Argentina e do Paraguai. No Brasil, além de $A$. comosus são encontradas todas as espécies do gênero Ananas, tanto na forma silvestre quanto cultivada, em várias regiões brasileiras (FERREIRA; CABRAL, 1993).

Atualmente, o abacaxi é extensivamente produzido em todos os países tropicais, o Brasil e as Filipinas são os maiores produtores mundiais (FOOD AND AGRICULTURE ORGANIZATION OF THE UNITED NATIONS STATISTICALDATABASE, 2010; INSTITUTO BRASILEIRO DE GEOGRAFIAE ESTATÍSTICA, 2012). No estado do Rio Grande do Sul, o Litoral Norte e a Microrregião de Santa Rosa se destacam como maiores produtores de abacaxi do estado. Na Figura 1, pode-se observar a distribuição da produção, em 2010.

A prática do cultivo do abacaxizeiro, porém, é mais antiga no Litoral Norte, o início datando da década de 1940. Os primeiros cultivos ocorreram na mesma época em que foi implementado, também, o cultivo da bananeira na região. $\mathrm{O}$ intuito era proporcionar aos agricultores uma opção economicamente viável, pois, à época, não havia outra cultura integrada às demais atividades de subsistência realizadas (SANTIN; PINHEIRO, 2009).

As primeiras plantações foram realizadas com a instalação de plantios pilotos, utilizando-se, provavelmente, a cultivar "Pérola". Esses primeiros abacaxizeiros passaram por um período de adaptação e seleção natural e artificial de algumas décadas, as plantas atualmente cultivadas são aquelas que melhor se ajustaram às condições de solo e clima da região do município de Terra de Areia (AMBROSINI; OLIVEIRA; FAVRETO, 2017; SANTIN; PINHEIRO, 2009). 


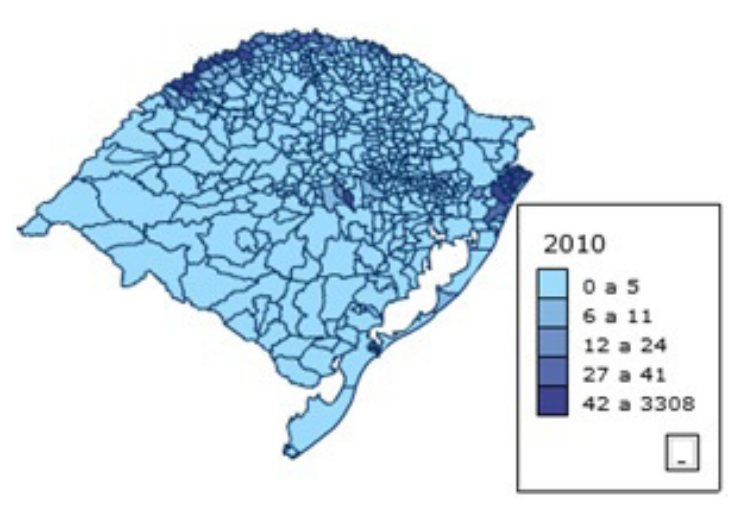

FIGURA 1 - Produção de abacaxi por município no Rio Grande do Sul, em número de frutos Fonte: Instituto Brasileiro de Geografia e Estatística (2012)

Em termos de importância econômica, a cultura do abacaxi contribui para a fixação do homem no meio rural (CUNHA, 2007), já que é desenvolvida em estabelecimentos rurais de pequeno porte, caracterizados por serem de agricultura familiar. O município de Terra de Areia é, atualmente, o maior produtor de abacaxi do estado com área colhida de 245 ha e produção superior a 3,3 milhões de frutos, em 2010 (INSTITUTO BRASILEIRO DE GEOGRAFIA E ESTATÍSTICA, 2012). A atividade envolve cerca de 80 famílias apenas, no referido município (SANTIN; PINHEIRO, 2009).

No que concerne ao consumo, parece haver reconhecimento e valorização do produto por parte dos consumidores devido às características gerais do fruto, como sabor adocicado proeminente. $\mathrm{O}$ reconhecimento levou à construção de uma reputação para o produto cuja origem é o litoral norte do RS, mas concentrando-se, especialmente, no município de Terra de Areia, de tal forma esse abacaxi é conhecido como "abacaxi terra de areia". É muito comum encontrar fruteiras e bancas em Porto Alegre (RS) e no litoral utilizando a referência “terra de areia" para 'qualificar' a oferta do abacaxi. Segundo alguns produtores que entrevistamos em outras etapas de nossa pesquisa, a denominação vem sendo utilizada, inclusive, para vender frutos que não têm origem na região, esses vendedores "de fora" se valem, assim, da reputação construída ao longo do tempo, de forma indevida.

Apesar de o abacaxi ter reputação junto ao consumidor e ser cultivado há quase 70 anos, existe pouca pesquisa sobre ele $^{5}$, havendo necessidade de se pesquisar,

${ }^{5}$ A portaria (236/2012) normatizando o zoneamento climático para a cultura, por exemplo, foi publicada em outubro de 2012. Até essa data, os produtores não tinham acesso ao Proagro, pois o abacaxizeiro não constava no zoneamento climático da região. conhecer melhor e documentar diferentes aspectos da cultura. Estes vão desde aspectos relativos ao cultivo, à história, bem como às formas de comercialização e os gargalos para venda e valorização do abacaxi. O presente trabalho pretende contribuir com o conhecimento acerca da percepção dos consumidores com relação ao produto, bem como, sobre como esses consumidores percebem a relação entre o produto e seu território de origem.

\section{REFERENCIAL TEÓRICO}

\subsection{Demanda por Atributos e Qualidade Relacionada à Origem}

Para a economia neoclássica, os bens são considerados objetos diretos de utilidade sobre os quais os consumidores operam suas escolhas, produto por produto. A escolha ótima é guiada pela maximização da utilidade do bem a partir dos seguintes elementos: i) características físicas, ii) data de disponibilidade e iii) lugar de disponibilidade.

A partir de um artigo de Akerlof (1970), a economia examina a hipótese da não homogeneidade dos bens. Em seu estudo sobre o mercado de automóveis usados, o autor coloca o problema em termos de qualidade, fator até então não examinado pela teoria. Os bens, sendo os mesmos, a escolha do consumidor se fará entre o bom e o mau automóvel (limão), o problema residindo no fato de não ser possível saber qual é a boa escolha, antes da compra, devido à assimetria de informações entre vendedores e compradores. Quando Lancaster coloca a questão de escolha entre idênticos, por exemplo, carros novos: uma Chevrolet cinza e uma Chevrolet vermelha, o problema muda de natureza, pois os dois bens apresentam a mesma qualidade, tendo 'apenas' cores diferentes. As cores, entretanto, influenciam a escolha dos consumidores.

Lancaster propõe o modelo de demanda por atributos. Ele considera que a utilidade de um bem é determinada de forma indireta por seus atributos ou características. "Utilidade ou ordem de preferências são assumidas para classificar coleções de características e, somente, para classificar coleções de bens indiretamente, através das características que eles possuem" "(LANCASTER, 1966, p. 133). Essa conversão é formalizada por uma proposição que considera o bem como uma matriz de características, dentre elas o preço. Seria mediante a análise dessas características que os consumidores poderiam operar suas escolhas.

6 «Utility or preference orderings are assumed to rank collection of characteristics and only to rank collections for goods indirectly trough the characteristics that they posses.» 
Voltando ao exemplo da Chevrolet, as cores são características objetivas, mas geram respostas subjetivas por parte dos consumidores. Segundo Lancaster, as características possuem uma dupla relação: de uma parte a relação com os bens, chamada 'técnica'; e de outra, a relação com os consumidores. A relação técnica pode ser avaliada de maneira objetiva, mas a relação com os consumidores depende da importância dada às características do bem,ou seja, as características são propriedades cuja importância está relacionada à sua capacidade de gerar uma resposta por parte dos consumidores - resposta que pode ser, inclusive, negativa. Ainda, os critérios utilizados para julgar as características mudam de acordo com diferentes grupos de consumidores (LANCASTER, 1991).

Para a economia da informação, as características ou atributos dos bens são classificados da seguinte forma: de pesquisa, de experiência e de crença. Os atributos de pesquisa são as informações sobre a qualidade do produto que estão disponíveis ao consumidor antes do ato da compra, como preço, tamanho ou cor. Os atributos de experiência são as informações sobre os produtos que os consumidores só podem verificar depois da compra, é o caso do gosto. Os atributos de crença são aqueles que não podem ser verificados nem antes, nem após o ato de compra ou consumo. Eles podem estar relacionados com o próprio produto, com o processo, ou mesmo com o sistema de produção desse bem (SIRIEX, 1999).

Em nosso estudo, optamos por analisar a percepção dos consumidores sobre o abacaxi utilizando a tipologia de Siriex (1999), que se aproxima muito daquela que acabamos de descrever, mas foi elaborada especificamente para produtos alimentares. A autora diferencia indicadores de qualidade e características de qualidade. Os indicadores são aqueles observáveis diretamente pelos consumidores, como aparência, cor, preço. As características de qualidade, por outro lado, não são diretamente observáveis. Algumas delas, entretanto, são passíveis de verificação por meio do consumo, é o que chamamos características tangíveis; são exemplos: sabor, frescor. As características consideradas intangíveis estão relacionadas à confiança que o consumidor tem nas informações que recebe sobre o produto, como o fato de que sua produção é sustentável, o que não pode ser verificado no ato de consumo.

No que se refere a produtos com reputação ligada à origem, os consumidores buscam, além das características e atributos mencionados, o que chamamos conteúdo patrimonial, o qual se exprime pela interação entre as dimensões histórico-cultural e físico-geográfica do seu território, é que chamamos efeito terroir. O efeito terroir é o resultado da interação entre um ambiente natural (base física das atividades) e as atividades humanas (que desenvolvem 'saberes' - savoir-faire, processos, cultivo, seleção, transformação de matérias primas) desenvolvidas pelos grupos que se sucederam no território. Os modos de organização social e suas representações completam a relação do produto com o seu lugar de origem (BARJOLLE; BOISSEAUX; DUFOUR, 1998), tema que aprofundaremos na próxima seção.

\subsection{Indicação Geográfica entre Dimensão Cultural e Física: Terroir, Valorização da Oferta, Preservação Ambiental e Cultural}

As pesquisas sobre a relação de produtos alimentares com seu território de origem apresentam duas tendências: a que prioriza a dimensão físico-geográfica do território e a que prioriza a dimensão histórico-cultural. A primeira se baseia em particularidades pedológicas e climáticas, pois considera esse o componente mais importante para determinar as especificidades do produto. As críticas a essa abordagem dizem respeito à delimitação do efeito terroir em porções homogêneas do território e sobre o limite de não considerar a dimensão temporal, inscrevendo esse produto apenas na dimensão espacial. A abordagem cultural mobiliza diferentes disciplinas para compreender e explicar a construção da tipicidade dos produtos. Para essa tendência, é importante considerar o espaço físico e as especificidades naturais entendendo que as práticas agronômicas e zootécnicas só podem se expressar por meio de técnicas desenvolvidas por grupos humanos ao longo da história desse espaço. A análise dos diferentes elementos que se relacionam, naturais e culturais, permite justificar assim a ancoragem espacial e temporal do produto e, também, compreender como ele adquiriu as características pelas quais o conhecemos. $O$ efeito terroir seria então a sinergia de fatores naturais e humanos que resultaram em processos de fabricação de produtos com forte identificação local (BÉRARD; MARCHENAY, 2007).

Nesse trabalho, partimos da noção francesa de terroir proposta por Barjolle, Boisseaux e Dufour (1998), pois ela busca integrar as duas vertentes, e analisar os produtos como fruto da interação entre fatores culturais (modos de cultivo, modos de preparo e de processamento dos alimentos, receitas); e fatores ambientais (características edafoclimáticas, variedades vegetais adaptadas, raças animais adaptadas, influência do solo e clima em características do produto). Do ponto de vista conceitual, logo, há duas dimensões que se combinam, quando abordamos as IG: dimensão físico-geográfica, dimensão histórico-cultural. Sabemos 
que nem sempre ambas estão presentes nos estudos sobre IG. Isso se deve, em parte, à novidade que, ainda, representa o conceito no país, mas, também, à diferença de percepção que as indicações suscitam nos diferentes atores envolvidos, seja na produção, seja no consumo.

No Brasil, Blume (2008), por exemplo, constatou, analisando o caso da vitivinicultura, que, para os atores da produção, a indicação da origem é determinada mais pela dimensão física do território do que por seus elementos culturais e históricos. Falcão e Révillion (2010) pesquisaram a percepção de enófilos a respeito da relação entre IG e qualidade dos vinhos. Os resultados mostram que, para a maioria dos entrevistados $(62 \%)$, os fatores edafoclimáticos seriam mais determinantes que fatores ligados à cultura e à história. Em contraste, um estudo feito com consumidores na França, apontou o fator "tempo e cultura", como o mais importante e influente em relação ao consumo de produtos portando IG. Isso apareceu de forma tão evidenciada, que os autores destacaram que estratégias de comunicação baseadas prioritariamente na dimensão físico-geográfica teriam pouca efetividade (AURIER; FORT; SIRIEIX, 2005).

Sabendo que existe uma lacuna entre as percepções, a montante e a jusante, propusemos pesquisar o conhecimento dos consumidores brasileiros acerca das IG, qual sua percepção a respeito da ferramenta e sua compreensão sobre a relação entre o produto e seu território de origem, levando em consideração as dimensões propostas pela noção de terroir acima descrita.

\section{METODOLOGIA}

A coleta de dados foi feita por meio de um questionário estruturado, construído a partir do referencial teórico apresentado. A metodologia seguiu o modelo 'survey', que se caracteriza pela interrogação direta aos entrevistados a respeito de seu comportamento frente a determinadas situações, intenções, atitudes, percepções. O protocolo desse tipo de pesquisa prevê que a coleta de dados primários seja feita mediante entrevistas, que podem ser aplicadas de diferentes formas: pessoal, telefone, correio, e-mail, internet (GIL, 2002; MALHOTRA, 2001).

Em nosso estudo, utilizamos a internet como meio de coleta, pela ferramenta Google Drive, que permite criar um formulário de questões em diferentes formatos (questões fechadas, abertas, lickert, entre outras), apresentando a vantagem de, ao final, gerar uma planilha com todas as respostas tabuladas.

A divulgação da pesquisa ocorreu de duas formas, primeiramente por mensagem de solicitação para preenchimento do questionário enviado via email, com o link da pesquisa, sob a técnica "bola de neve", que repousa na solicitação de que os atingidos reenviem a seus contatos pessoais a mensagem e o link. A mensagem de solicitação para preenchimento e o link para a pesquisa foram divulgados, também, em meios de comunicação e redes sociais, pelo Setor de Comunicação da Fepagro.

\section{RESULTADOS}

\section{1 Perfil e Hábitos de Consumo}

O questionário ficou disponível para preenchimento durante pouco mais dois meses (entre 01 de setembro de 2015 e 11 de novembro de 2015). Durante o período, 210 pessoas acessaram o link e responderam às perguntas propostas.

A maior parte dos respondentes tem entre 26 a 45 anos; quase dois terços são mulheres; a renda familiar é acima da média da população brasileira, mais de $40 \%$ percebendo entre 4 a 10 salários mínimos mensais; a situação domiciliar mais frequente é casal com filho(s), mais de $70 \%$ da amostra tem curso de pós-graduação e mais de 50\% é habitante da cidade de Porto Alegre: 111 pessoas. É provável que a metodologia tenha influenciado na composição da amostra, uma vez que os contatos de pesquisadores tenham repassado a seus contatos a pesquisa. Podemos pensar, também, que as pessoas do meio acadêmico podem ter se interessado mais em responder a pesquisa, o que determinou a composição da amostra. O Quadro 1 apresenta o perfil socioeconômico da amostra.

Perguntamos também sobre os hábitos de compra dos consumidores no que se refere a três categorias de produtos: (i) leite e derivados, (ii) carne, (iii) frutas, verduras e legumes. Os principais canais de distribuição de alimentos no Brasil são: hipermercados, supermercados, lojas de especialidades (açougues, padarias, varejões, entre outros), mercearias e feiras-livres. A principal diferença entre supermercados e feiras e lojas especializadas seria o atendimento. Os supermercados "são considerados varejos de autosserviço, onde o próprio consumidor se serve, colocando os itens escolhidos em carrinhos ou cestas para, ao final das compras, passarem no check-out e efetuarem o pagamento" (MOURA; SILVA; BATALHA, 2006, p. 2).

Em nosso estudo, utilizamos categorias diferentes, priorizando a especialização do varejo em relação ao produto e a proximidade entre produtores e consumidores. As lojas de especialidades oferecem maior variedade de um determinado item alimentar, sua escolha pelo consumidor denota uma 
QUADRO 1 - Perfil socioeconômico da amostra

\begin{tabular}{|c|c|}
\hline Faixa etária da amostra & $\%$ \\
\hline Até 25 anos & 8 \\
\hline De 26 a 35 anos & 31 \\
\hline De 36 a 45 anos & 28 \\
\hline De 46 a 55 anos & 21 \\
\hline Acima de 55 anos & 12 \\
\hline Gênero & $\%$ \\
\hline Feminino & 67 \\
\hline Masculino & 33 \\
\hline Renda & $\%$ \\
\hline Até 2 salários mínimos & 3 \\
\hline De 2 a 4 salários mínimos & 12 \\
\hline De 4 a 10 salários mínimos & 43 \\
\hline De 10 a 20 salários mínimos & 30 \\
\hline Mais de 20 salários mínimos & 12 \\
\hline Com quem reside & $\%$ \\
\hline Com companheira(o) (esposa, marido) & 26 \\
\hline Com os pais & 9 \\
\hline Companheira(o) e filhos & 35 \\
\hline Diversos familiares & 6 \\
\hline Somente com os filhos & 5 \\
\hline Sozinho & 14 \\
\hline Amigos & 4 \\
\hline Outro & 1 \\
\hline Escolaridade & $\%$ \\
\hline Ensino fundamental & 1 \\
\hline Ensino médio & 5 \\
\hline Graduação & 20 \\
\hline Pós-graduação & 73 \\
\hline Estados onde residem & $\mathrm{n}$ \\
\hline $\mathrm{RS}$ & 204 \\
\hline $\mathrm{SC}, \mathrm{RJ}, \mathrm{DF}, \mathrm{SP}$ & 6 \\
\hline Total & 210 \\
\hline
\end{tabular}

Fonte: Dados de pesquisa

maior atenção com o item em questão. A opção por feiras ou pela compra direta (de produtores) constitui um atalho na cadeia de distribuição predominante, tende a remunerar melhor o produtor e a favorecer a construção de uma relação de proximidade/confiança (MARSDEN; BANKS; BRISTROW, 2000; SONINO; MARSDEN, 2006).

Nossos resultados mostram que, para as três categorias de produtos demandadas, o supermercado é menos importante apenas para a compra de "frutas, verduras e legumes", ainda assim, é utilizado, preferencialmente, por $60 \%$ dos entrevistados (Tabela 1). Para a compra de leite e seus derivados, quase $90 \%$ dos entrevistados costumam utilizar o supermercado, para compra de carnes são $70 \%$ a utilizar esse canal com maior frequência.

Esse resultado demonstra que, mesmo para classes de produtos que contam com lojas especializadas, como açougues no caso de carnes, o supermercado acaba prevalecendo. A mudança do estilo de vida urbano é um dos fatores que ajuda a entender esse hábito. A busca por praticidade ou a falta de tempo levam os consumidores a fazer a compra de quase todos os gêneros em um lugar apenas (CONFEDERAÇÃO NACIONAL DA AGRICULTURA, 2011; LIMA-FILHO et al., 2013). Paralelamente, temos o crescimento acelerado das grandes redes de supermercado no país, a partir do início dos anos 1990. Sua participação no total do varejo de alimentos, que era de 5 a $10 \%$ nesse período, atualmente ultrapassa os $60 \%$ (REARDON, 2011).

Entretanto, verificamos que, para a categoria "frutas, verduras e legumes", a compra direta de produtores e as feiras, ainda, são as formas de abastecimento preferidas de quase um quarto dos entrevistados. Acrescentando lojas especializadas, como fruteiras, temos mais de $35 \%$ dos consumidores a comprar com maior frequência itens dessa categoria fora do supermercado. Os resultados encontrados são semelhantes aos de Souza et al. (2008) que pesquisou hábitos de compra de frutas, verduras e legumes em municípios da região central do RS. Lembramos, também, que esse é o segmento com menor participação das grandes redes varejistas, em comparação a lácteos e derivados, carnes e commodities não perecíveis (REARDON; BERDEGUÉ, 2002).

No que se refere, especificamente, à compra do abacaxi "terra de areia", a maior parte dos consumidores não utiliza o varejo tradicional. Mais de $60 \%$ costuma comprá-lo em tendas e caminhões localizados na região do Litoral Norte ou em outras cidades, como Porto Alegre, Tabela 2 - Estabelecimentos usados para compra de "abacaxi terra de areia".

\section{2 "Abacaxi Terra de Areia": Além do Sabor, Sustentabilidade Ambiental e Social}

Para os consumidores ouvidos, o atributo mais importante na compra de frutas em geral é uma característica de qualidade tangível: o sabor, "importante" e "muito importante" para 94\%. 
TABELA 1 - Canais de abastecimento de alimentos utilizados pelos consumidores

\begin{tabular}{cccc}
\hline Onde você costuma comprar COM MAIOR FREQUÊNCIA & $\begin{array}{c}\text { Leite e derivados } \\
(\%)\end{array}$ & $\begin{array}{c}\text { Carnes } \\
(\%)\end{array}$ & $\begin{array}{c}\text { Frutas, verduras, } \\
\text { legumes }(\%)\end{array}$ \\
\hline Diretamente do produtor ou em feiras & 8,10 & 0,95 & 24,76 \\
Em lojas especializadas & 0,48 & 18,57 & 10,95 \\
Esse produto vem de amigos, família ou minha propriedade & 1,90 & 5,71 & 3,33 \\
Minimercado, supermercado, hipermercado & 87,14 & 70,00 & 60,95 \\
Não consumo esse produto & 1,43 & 4,76 & 0,00 \\
Outro & 0,95 & 0,00 & 0,00 \\
\hline Total & 100 & 100 & 100 \\
\hline
\end{tabular}

Fonte: Dados de pesquisa

TABELA 2 - Estabelecimentos usados para compra de "abacaxi terra de areia"

\begin{tabular}{cc}
\hline Onde costuma comprar « abacaxi terra de areia »? & $\%$ \\
\hline Diretamente do produtor & 2,9 \\
Através de amigos ou família & 1,4 \\
Feira & 8,6 \\
Fruteiras & 6,2 \\
Supermercado, minimercado & 7,6 \\
Tendas na estrada ou em cidades do Litoral do RS & 34,3 \\
Tendas/caminhões em outras cidades fora do Litoral & 27,1 \\
Outro & 2,4 \\
Sem resposta & 9,5 \\
\hline Total & 100 \\
\hline
\end{tabular}

Fonte: Dados de pesquisa

A aparência, um indicador de qualidade, foi considerado "importante" ou "muito importante" para $74 \%$ dos entrevistados. Em seguida, os consumidores apontaram como determinante para a compra de frutas características intangíveis: "uso de métodos de produção que respeitem o meio ambiente" (70\% entre "muito importante" e "importante") e "apoio aos pequenos produtores" $(62 \%$ entre "muito importante" e "importante"). O tamanho, outro indicador de qualidade, é o atributo menos levado em consideração no momento da compra, e menos relevante apenas que o preço (Figura 2).

Em pesquisa com consumidores de frutas, legumes e verduras da região central do RS, Souza et al. (2008) encontraram resultados um pouco diferentes, embora sabor e aparência também tenham aparecido como as características que os consumidores mais levam em consideração no momento da compra. Nesse estudo, o atributo que apareceu como "muito importante" e "importante" para 94\% dos entrevistados foi aparência, depois: sabor $(86 \%)$, preço $(77 \%)$, aspectos nutricionais (76\%). Lemos (2011), em sua dissertação de mestrado, aponta estudos realizados na Islândia, Reino Unido e Brasil, onde o sabor aparece como atributo determinante no consumo de frutas.

Esse mesmo atributo é aquele que os consumidores do "abacaxi terra de areia" reconhecem como o diferencial desse fruto. Dentre os entrevistados, 90\% (188/210) declararam conhecer o "abacaxi terra de areia", e $88 \%$ (186/210) já consumiram o produto. Segundo a percepção dos consumidores, as características mais marcantes do "abacaxi terra de areia" são: i) "o sabor, melhor que os demais" (85\%); ii) "o tamanho, em geral menor que os demais" (75\%) e iii) "o cheiro, mais perfumado que outras variedades que eles conhecem" (81\%).

A importância do atributo sabor aparece também quando perguntamos aos consumidores suas motivações para consumir o "abacaxi terra de areia". A maioria dos consumidores, mais de $92 \%$ (Figura 3), busca consumir um produto cujo sabor aprecia, mas enxerga, também, no produto um alimento um saudável. As motivações ligadas ao sabor e à busca pela saudabilidade estão relacionadas a valores de consumo chamados utilitários, pois cumprem uma função instrumental e são um segmento dentro de uma tendência de consumo mundial que chamamos Saudabilidade+Bem-estar (VIALTA et al., 2010). O interesse por alimentos não processados, orgânicos ou funcionais fazem parte dessa tendência. Para essa classe de valores de consumo, os beneficiários são os próprios consumidores (AURIER; EVRARD; N'GOALA, 2004).

Entretanto, outros atributos de qualidade intangíveis, relacionados à sustentabilidade ambiental, à tradição cultural, ao apoio à economia local, também, motivam o consumo desse produto. Os consumidores consideram 
que o "abacaxi terra de areia" é um produto tradicional, inserido na história do Litoral Norte do RS, cultivado por agricultores familiares, de forma sustentável e respeitosa ao meio ambiente. $\mathrm{O}$ apoio à economia local também é um fator que os consumidores levam em conta: $67 \%$ concorda que sua escolha favorece a economia da região.

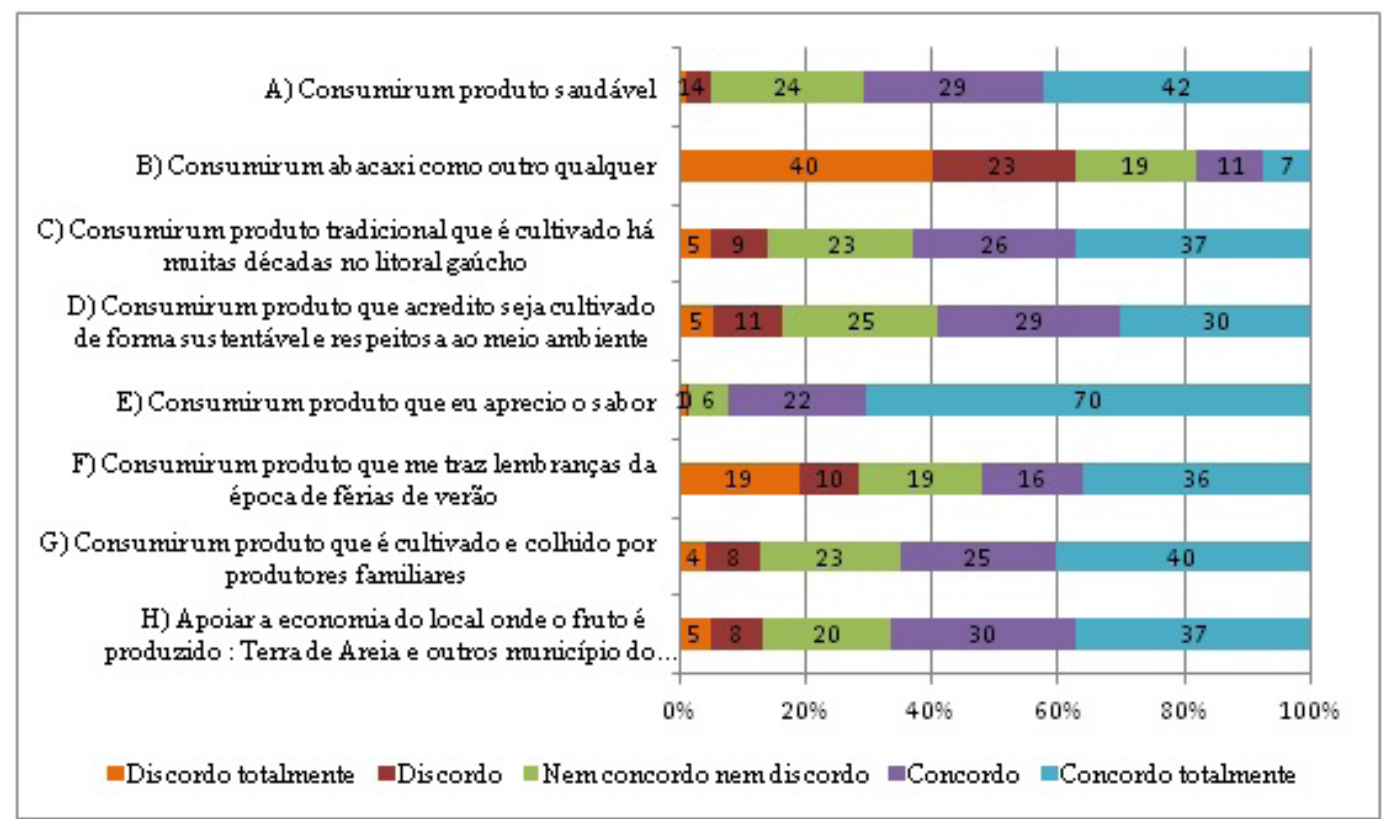

FIGURA 2 - Atributos considerados na compra de frutas (\%)

Fonte: Dados de pesquisa

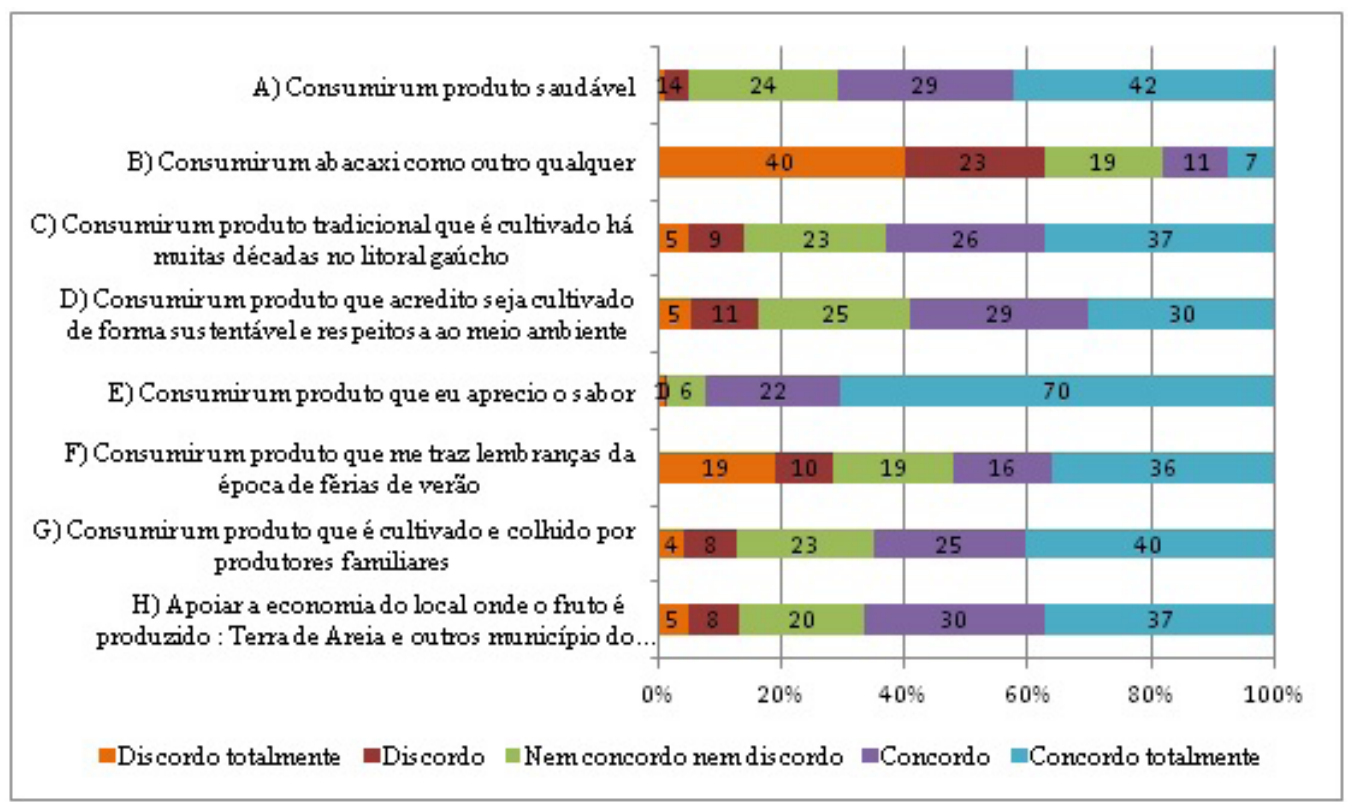

FIGURA 3 - Motivações para o consumo do "abacaxi terra de areia" (\%)

Fonte: Dados de pesquisa 
O reconhecimento por parte dos consumidores de características intangíveis e a busca pelo consumo de um produto que satisfaz motivações ligadas à preservação ambiental e cultural estão relacionadas à tendência de consumo que chamamos Sustentabilidade+Ética. Essa tendência mobiliza valores de consumo ligados à responsabilidade social e ambiental, cuja função está relacionada ao engajamento ético e político. Nesse caso, os beneficiários da escolha de um produto que cumpre os requisitos são, além dos consumidores que se sentem engajados e agindo por uma causa, os produtores, a economia local, o meio ambiente (AURIER; EVRARD; N'GOALA, 2004).

De fato, a literatura tem mostrado que, nas duas últimas décadas, depois do auge da globalização, a "origem" tem desempenhado um papel de engajamento social, econômico e político, na medida em que as relações entre produtores e consumidores visam a um tipo de proximidade fundada na re-ancoragem de produtos ao local, levando em conta o contexto ambiental e comunitário (BESSIÈRE, 1998; FONTE, 2008; PARROT; WILSON; MURDOCH, 2002; ROOS; TERRAGNI; TORJUSEN, 2007). No domínio alimentar, esse caráter de movimento de reação parece assumir uma amplitude ainda maior. Certos autores interpretam esse movimento como motivado por um certo romantismo, um desejo de retorno a valores baseados em sentimentos de nostalgia com relação ao "campo", ou ao rural, e sua promessa de originalidade, tipicidade, segurança, que seria oposto ao universo frio e incerto das relações puramente econômicas (HINRICHS, 2000; HOLT; AMILIEN, 2007; MURDOCH; MIELE, 1999).

No que se refere ao "abacaxi terra de areia", percebemos que, por parte dos consumidores há o reconhecimento de que as características do produto vão além dos atributos tangíveis, como sabor, e passam pelo reconhecimento de caraterísticas intangíveis que fazem parte da ancoragem territorial do produto, constituindo-o como um patrimônio local. A motivação para consumir o "abacaxi terra de areia" demonstra, claramente, que os consumidores buscam uma fruta que satisfaça sua necessidade pessoal, mas que seja cultivada por agricultores familiares e que faça parte da história, cultura e economia local. Esse conjunto de características e elementos diferenciam o abacaxi de Terra de Areia com relação a outros na compreensão dos consumidores e tornam o produto singular.

\subsection{Indicação Geográfica: Preserva a Cultura Local e Agrega Valor ao Produto}

Primeiramente, buscamos verificar se os consumidores tinham alguma familiaridade com produtos portadores de IG. Para isso, perguntamos se eles conheciam produtos com IG. Entre os respondentes, $65 \%$ disseram "sim", 35\% disseram "não"; nenhum deixou a questão sem resposta. Em seguida perguntamos se eles consumiam algum produto com IG, obtivemos para "sim" e "não" resultado igual: $48 \%, 4 \%$ não responderam.

Em pesquisa realizada em 2009, para a mesma pergunta, sobre a familiaridade com produtos com IG, no estado do Rio Grande do Sul, Brandão obteve 37,9\% de "sim" e $60,3 \%$ de "não". Sobre o percentual dos consumidores pesquisados que já haviam consumido produtos com IG, os resultados dessa mesma pesquisa foram: $34,9 \%$ de "sim"; $55,9 \%$ de "não"; $9,6 \%$ não responderam. Moraes et al. (2013), em pesquisa sobre IG de carnes, no estado do Mato Grosso do Sul, obteve os seguintes resultados: $81 \%$ nunca ouviram falar sobre IG, dos $19 \%$ que já conheciam produtos com IG, $41 \%$ já haviam consumido. Observando-se, portanto, alto percentual de desconhecimento dos consumidores.

A diferença dos resultados pode ser atribuída ao tempo decorrido entre os estudos, já que o perfil das amostras em termos de escolaridade é semelhante, mais de $90 \%$ com graduação e pós-graduação. Podemos supor que os entrevistados têm maior acesso a informação do que a média da população. Entretanto, à época a ferramenta poderia ser considerada uma novidade e, portanto, menos conhecida pelos consumidores brasileiros em geral. É preciso lembrar que a primeira IG brasileira foi registrada em 2002 (Vale dos Vinhedos), em 2009 havia apenas 6, hoje são 30 IG brasileiras registradas.

Para verificar se as respostas afirmativas se traduziam em conhecimento sobre a oferta de produtos com IG, solicitamos que os consumidores citassem exemplos: $61 \%$ da amostra foram capazes de responder a essa solicitação, obtivemos 245 referências. Globalmente, as respostas demonstraram que os consumidores associam IG com origens e produtos alimentares, muito mais pela reputação, que pelo registro normativo.

Os tipos de produtos mais citados foram vinhos e queijos, seguidos por carnes e doces. Foram 65 referências a vinhos, 21 delas se referindo ao vinho do Vale dos Vinhedos (RS); 14 citando "vinho", sem outra especificação; 9 citaram "vinho da Serra Gaúcha", e 6 "vinho do Porto". Note-se que a Serra Gaúcha não é 
objeto de $\mathrm{IG}$, embora a região abrigue não menos que 5 IG já registradas para vinhos e espumantes: "Altos Montes", "Farroupilha", "Monte Belo", "Pinto Bandeira", e "Vale dos Vinhedos". Nessa categoria, as únicas IG de fato citadas foram "Vale dos Vinhedos", a primeira IG de vinhos brasileira registrada no Ministério e a primeira a obter uma Denominação de Origem, e "Porto", uma Denominação de Origem portuguesa registrada no Brasil.

Entre os queijos, obtivemos 48 referências, e a maior parte delas (13 citações) citou um queijo tradicional produzido desde o final do século XVII no RS (AMBROSINI; FILIPPI; MIGUEL, 2009), mas que não porta IG, oficialmente: o Queijo Serrano. Outro queijo bem lembrado pelos consumidores (13 citações) foi o "queijo minas", que não é uma IG. Em menor número os consumidores citaram "Serra da Canastra", (7 citações), e "Queijo do Serro", (2 citações), a última é uma IG registrada, a primeira refere-se a IG "Canastra".

Outros produtos citados merecem registro: o Arroz do Litoral Norte Gaúcho, os Doces de Pelotas e a Carne do Pampa. Para a carne, nenhuma referência utilizou a IG registrada "Pampa Gaúcho da Campanha Meridional", houve citações a "Carne do Pampa", "Carne dos Pampas", "Carne da Fronteira" e "Carne da Campanha".
É interessante observar, também, que a maior parte dos exemplos lembrados pelos consumidores refere-se a produtos brasileiros. A citação de produtos como Queijo Gruyère, Parmigiano Regiano, Presunto de Parma ou Jamon Ibérico, reunidas, mal passaram de uma dezena de referências no total. Entretanto, produtos bastante tradicionais e que não têm reconhecimento normativo, como o Queijo Serrano, foram bastante lembrados. Houve referências também ao "pêssego da Vila Nova" (Porto Alegre), à "maçã de Vacaria" (RS), à "rapadura de Santo Antônio da Patrulha" (RS).

Apesar dos consumidores, aparentemente, não conseguirem fazer a distinção entre o normativo e a reputação tácita de produtos, os entrevistados tendem a julgar a IG como uma ferramenta interessante, tanto para consumidores, quanto para produtores. Para a grande maioria, a IG: i) agrega valor ao produto; ii) é garantia de autenticidade; iii) contribui para melhorar a renda do produtor e, também, para iv) a preservação de culturas tradicionais. A maior parte dos entrevistados discorda que esse mecanismo sirva apenas para proteger produtos europeus. Sobre sua disposição em pagar mais por esse diferencial, muitos ficaram neutros, mas a maioria respondeu de forma favorável (Figura 4).

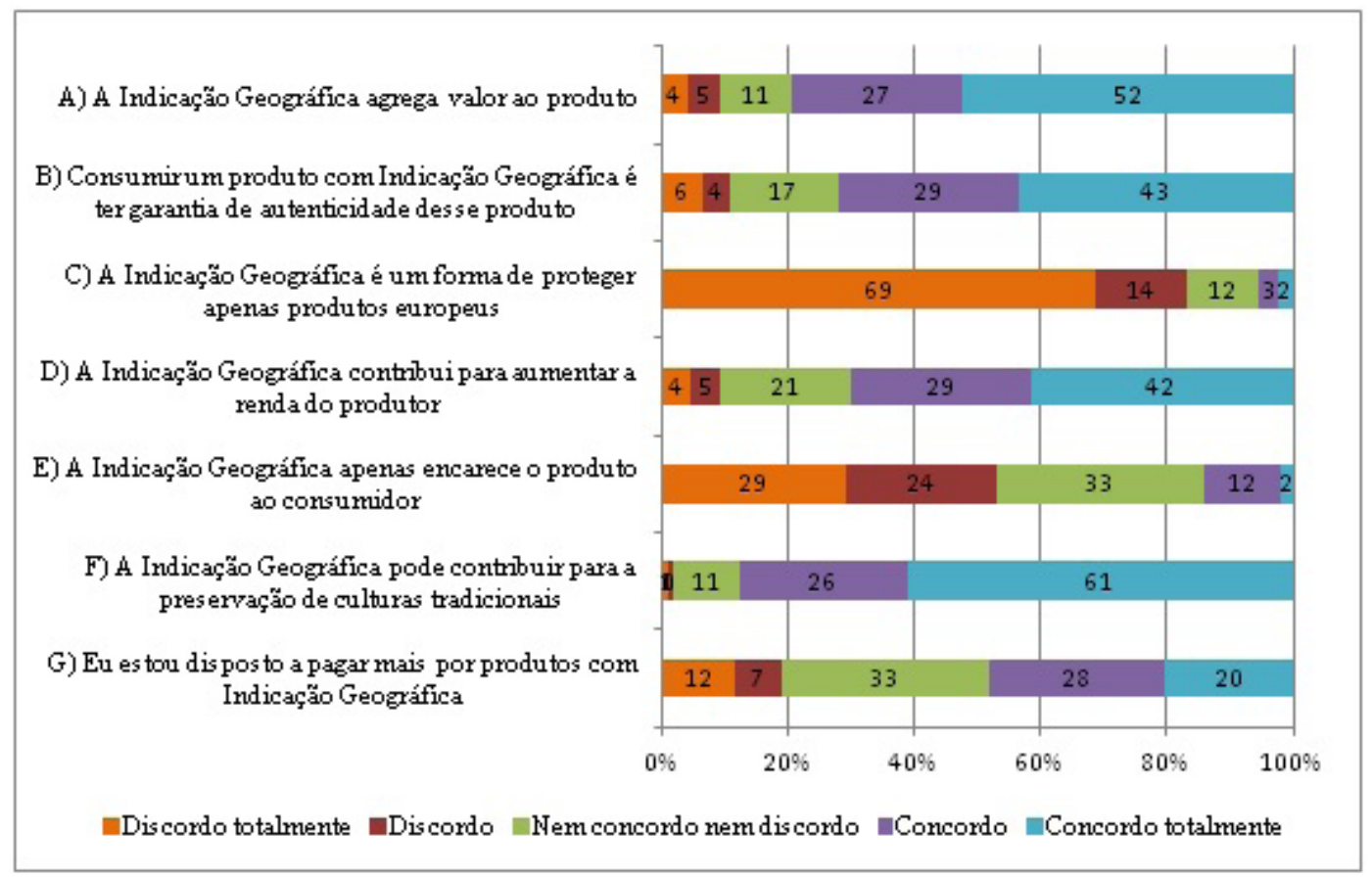

FIGURA 4 - Percepção dos consumidores sobre IG (\%)

Fonte: Dados de pesquisa

Organizações Rurais \& Agroindustriais, Lavras, v. 19, n. 2, p. 109-125, 2017 
Por fim, propusemos uma série de afirmativas sobre a relação do "abacaxi terra de areia" com sua origem, o objetivo era verificar se os consumidores percebem a influência das dimensões que compõem o território de origem do produto, baseando-se na noção de terroir.

Como vemos pela Figura 5, a maioria dos consumidores do "abacaxi terra de areia" percebem que a sinergia dos fatores naturais e humanos é determinante na expressão das características que diferenciam o produto. Quase $80 \%$ dos entrevistados julgam determinantes as condições climáticas da região de Terra de Areia, ou seja, a dimensão físico-geográfica. $45 \%$ acreditam que as práticas agronômicas empregadas são responsáveis pelas características do abacaxi, um reconhecimento ao saber-fazer desenvolvido ao longo de anos de cultivo do produto. Isso é reforçado pelo fato de que $85 \%$ dos entrevistados julgam que o cultivo do abacaxi faz parte da cultura local, reconhecendo que esse produto está inserido na história do território (dimensão histórico-cultural). Os consumidores, entretanto não se sentiram seguros em discordar da possibilidade de que um abacaxi com as mesmas características poderia ser obtido em outro local: $37 \%$ não concordaram, nem discordaram; o mesmo percentual discordou da possibilidade.
Os resultados são compatíveis com a literatura que analisa a produção alimentar e a construção da qualidade em torno de certificações ligadas à origem, como a IG. Segundo Valceschini (2000) a qualidade expressada pela IG tem uma essência "tradicionalista", que expressa a continuidade de práticas "preservadas" em espaços delimitados, frutos de uma longa acumulação de saber e saber-fazer locais. "Essa referência à constância de práticas estaria em ruptura com a [noção] de qualidade em outros setores industriais" (VALCESCHINI, 2000, p. 493).

Como nos referimos na primeira parte desse trabalho, os produtos típicos, de terroir, mobilizam uma relação complexa entre tempo e espaço, de onde surge a noção de patrimônio, o qual é uma fonte de diferenciação no mercado (BÉRARD et al., 2005; MUCHNIK, 2006; PECQUEUR, 1992). A valorização dessa oferta pode contribuir para processos de desenvolvimento sustentável em bases ecológicas e culturais (SACHET, 2016). Nossos resultados mostram que a IG tem potencial para se constituir em ferramenta para a proteção de saberes e práticas culturais, pois encontra respaldo junto aos consumidores.

${ }^{7}$ « Cette référence à la constance des pratiques est en rupture avec ce qu'est la qualité dans les autres secteurs industriels. »

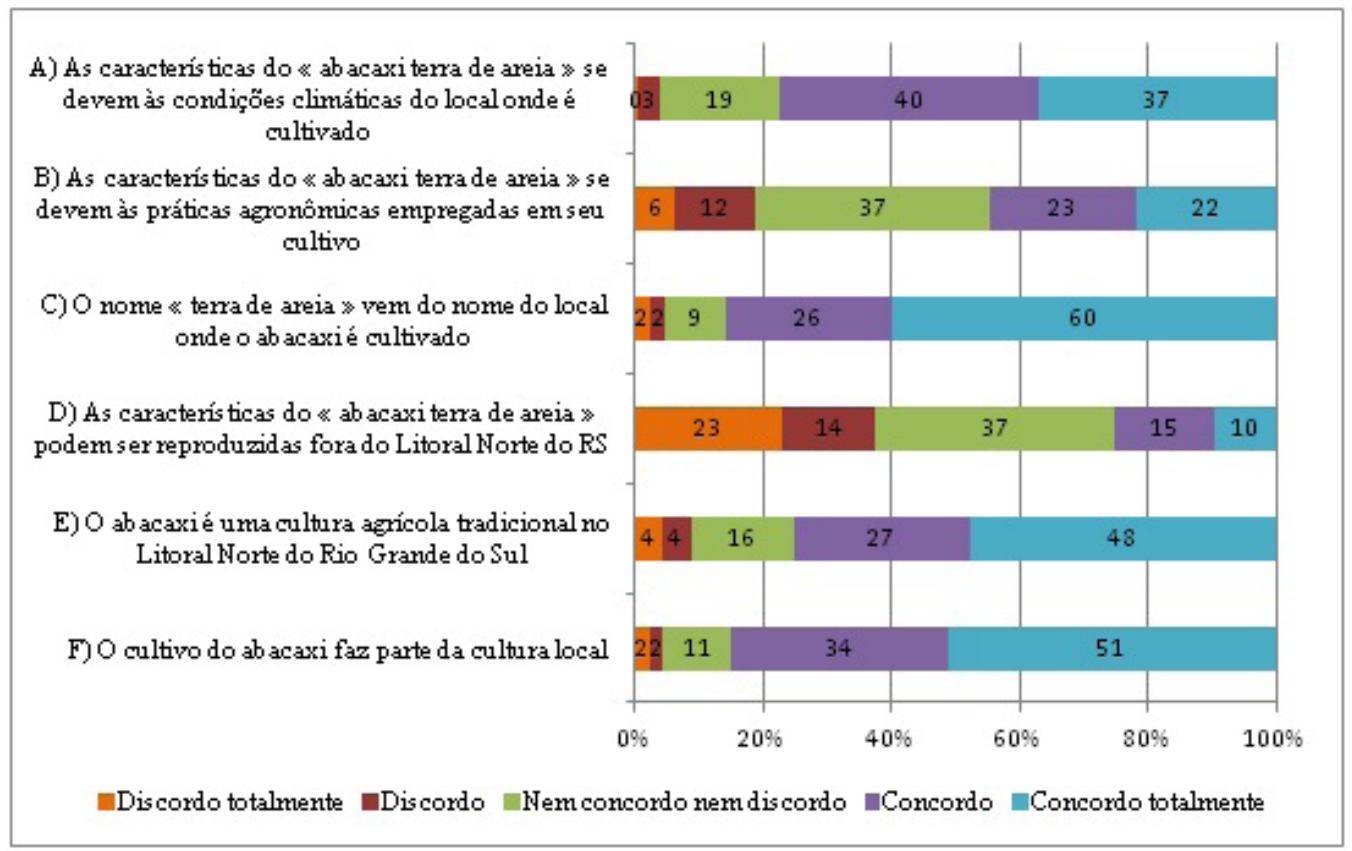

FIGURA 5 - Relação entre o "abacaxi terra de areia" e sua origem (\%) Fonte: Dados de pesquisa

Organizações Rurais \& Agroindustriais, Lavras, v. 19, n. 2, p. 109-125, 2017 
Entretanto, para que a IG possa contribuir efetivamente para esse processo como um instrumento de sinalização aos consumidores, é preciso avançar no delineamento do arcabouço normativo. Comparando os processos formais e metodológicos na obtenção de IG, Matos (2016) alerta para a necessidade de guardar uma equivalência, visando ao fortalecimento da IG no Brasil e evitando que a falta de alinhamento possa prejudicar o acesso a mercado internacionais. Se, por um lado, a legislação brasileira tem se mostrado atenta à influência dos fatores naturais na expressão de características do produto, a relação com a história e a cultura, e mesmo a preservação de saberes tem tido menos atenção. A não comprovação dos fatores humanos enfraquece a IG "como um instituto que protege o conhecimento humano e a diferença que seu saber fazer faz no espaço reconhecido para proteção" (MATOS; LA ROVERE, 2017, p. 20).

\section{CONSIDERAÇÕES FINAIS}

Nosso objetivo foi contribuir para o debate brasileiro acerca da IG, como ferramenta de proteção e valorização de produtos alimentares enquanto patrimônios locais, trazendo resultados sobre a percepção dos consumidores a respeito de um fruto com forte reputação local, qual seja: o "abacaxi terra de areia".

Em termos teóricos, a utilização de Lancaster e sua proposição de demanda por atributos revelou-se apropriada, pois permitiu distinguir, por meio de características, o "abacaxi terra de areia" de outras variedades, segundo a percepção dos consumidores. O referencial sobre terroir, utilizado, sobretudo, na caracterização da oferta alimentar, mobilizado em nosso estudo junto aos consumidores mostra resultados interessantes. Sua compreensão é relevante, quando levamos em consideração as expectativas geradas em termos de benefícios locais quando do requerimento ou obtenção de uma IG e pode subsidiar estratégias comunicação por parte dos atores envolvidos na produção.

Nossos resultados mostram que o "abacaxi terra de areia" construiu, ao longo do tempo, uma reputação muito positiva entre os consumidores. Colocar em evidência sua origem é uma estratégia para diferenciar e qualificar a oferta de abacaxi. As motivações ligadas ao consumo do abacaxi estão relacionadas a características que motivam o consumo de outras frutas, como o sabor e a busca por um alimento saudável. Entretanto, a importância dada pelos consumidores ao fato de se tratar de cultura tradicional do Litoral Norte do RS, desenvolvida por agricultores familiares, cujo consumo favorece a economia local, deixa claro que iniciativas de valorização e incentivo ao cultivo do abacaxi no Litoral Norte do RS devem priorizar métodos de produção sustentáveis do ponto de vista ambiental, favorecendo os produtores familiares, e, dessa forma, permitindo preservação do conteúdo patrimonial construído pelo "abacaxi terra de areia". A pesquisa demonstrou, também, que a maioria dos consumidores do "abacaxi terra de areia" percebem a relevância das dimensões, tanto físico-geográfica, quanto histórico-cultural do território na expressão das características que diferenciam o produto.

A bibliografia sobre o tema aponta as IG como instrumento de valorização e proteção de produtos alimentares, mas também como ferramenta para preservação de sistemas produtivos tradicionais e mais sustentáveis ambientalmente, os quais representam a expressão cultural de um território. $\mathrm{O}$ fato de os consumidores reconhecerem que as IG podem, sim, contribuir na preservação de culturas tradicionais confirma a assertiva e reforça o resultado anterior. Ainda que os respondentes tenham usado a reputação tácita de alguns produtos como sinônimo de IG, os resultados mostram, igualmente, que eles têm uma percepção favorável a respeito da ferramenta e julgam que ela pode beneficiar consumidores (garantia de autenticidade) e produtores (contribui para melhorar a renda do produtor). Assim, é importante que os agentes se apropriem "desses sinais, de grande valor no mercado internacional, [do contrário] muito de nossas produções locais com potencial distintivo continuarão fadadas a serem apenas commodities" (BARBOSA; DUPIM; PERALTA, 2016, p. 186).

Um dos limites da pesquisa foi o fato de termos atingido uma amostra na qual os consumidores apresentavam renda e escolaridade mais elevada que média da população brasileira. Os resultados podem ter refletido a percepção de uma parcela dos consumidores mais atenta a fatores como saudabilidade, bem-estar, sustentabilidade e com maior acesso a informações, portanto mais familiarizada com IG. Entretanto, esse perfil corresponde aos consumidores que teriam renda para remunerar melhor essa oferta. Por outro lado, um trabalho de comunicação visando a reforçar a reputação do "abacaxi terra de areia" para o público em geral deve trabalhar de forma simples e clara a relação entre o produto, suas características e seu território de origem.

\section{AGRADECIMENTO}

Os autores gostariam de reconhecer a contribuição dos pareceristas anônimos que avaliaram o presente trabalho para a publicação, pois seus apontamentos e sugestões contribuíram de forma relevante para aprimorá-lo. 


\section{REFERÊNCIAS}

AKERLOF, G. A. The market of lemons: quality uncertainty and market mechanism. The Quartely Journal of Economics, Oxford, v. 84, n. 3, p. 488-500, Aug. 1970.

AMBROSINI, L. B.; OLIVEIRA, C. A. O.; FAVRETO, R. Evolução dos sistemas agrários no território de produção do "abacaxi terra de areia" no litoral do Rio Grande do Sul. Desenvolvimento Regional em Debate, Contestado, v. 7, n. 1, p. 25-50, maio 2017.

AMBROSINI, L. B.; FILIPPI, E. E.; MIGUEL, L. A. Produção de Queijo Serrano: estratégia de reprodução social dos pecuaristas familiares do Sul do Brasil sob a perspectiva multidisciplinar do SIAL - Sistema Agroalimentar Localizado. Estudo \& Debate, Lajeado, v. 16, n. 2, p. 27-54, 2009.

ANJOS, F. S. et al. Indicações geográficas e desenvolvimento territorial: o caso dos vinhos e espumantes de Pinto Bandeira. In: VIEIRA, A. C. P.; BRUCH, K. L. (Org.). Indicações geográficas, signos coletivos e desenvolvimento. Lisboa: Editora IBPI, 2015. p. 206-224.

São as indicações geográficas um instrumento para o desenvolvimento dos territórios? Estudo de caso sobre duas experiências no estado do Rio Grande do Sul. Política \& Sociedade, Florianópolis, v. 13, n. 26, p. 163 193, jan./abr. 2014.

AURIER, P.; EVRARD, Y.; N'GOALA, G. Comprendre et mesurer la valeur du point de vue du consommateur. Recherche et Applications en Marketing, Oxford, v. 19, n. 3, p. 1-20, Sept. 2004.

AURIER, P.; FORT, F.; SIRIEIX, L. Exploring terroir product meanings for the consumer. Anthropology of Food, France, n. 4, May 2005. Disponível em: $<$ http://aof. revues. org/sommaire34.html . Acesso em: 10 mar. 2015.

BARBOSA, P. M. S. Marcas, indicações geográficas, selos e certificações de rastreabilidade em busca da certeza da origem e do conteúdo: o caso do café da região do Cerrado Mineiro. 2015. 236 f. Tese (Doutorado em Biotecnologia Vegetal) - Universidade Federal do Rio de Janeiro, Rio de Janeiro, 2015.
BARBOSA, P. M. S.; DUPIM, L. C.; PERALTA, P. P. Marcas e indicações geográficas: conflitos de registrabilidade nos 20 anos da LPI. In: LOCATELLI, L. (Org.). Indicações geográficas: desafios e perspectivas nos 20 anos da lei de propriedade industrial. Rio de Janeiro: Editora Lumen Júris, 2016. p. 157-188.

BARJOLLE, D.; BOISSEAUX, S.; DUFOUR, M. Le lien au terroir. Bilan des travaux de recherche. Zurique: Institut D'économie Rurale, 1998. 32 p.

BELAS, C. A.; WILKINSON, J. Indicações geográficas e a valorização comercial do artesanato em Capim-dourado no Jalapão. Sustentabilidade em Debate, Brasília, v. 5, n. 3, p. 56-78, set./dez. 2014.

BERARD, L. et al. Le panier de biens: une construction patrimoniale et territorial, l'exemple de la Bresse. In: SYMPOSIUM INTERNATIONAL TERRITOIRES ET ENJEUX DU DÉVELOPPEMENT RÉGIONAL, 2005, Lyon. Anais... Lyon: INRA-PSDR, 2005. p. 20.

BERARD, L.; MARCHENAY, P. Produits de terroir : comprendre et agir. Bourg-en-Bresse: CNRS, 2007. 61 p.

BERTONCELLO, A. G.; SILVA, K. F. R.; GODINHO, A. M. M. G. Indicação geográfica protegida: agrega valor ao produto e induz ao desenvolvimento regional? $\mathrm{O}$ caso da cachaça de Paraty. Desafio Online, Campo Grande, v. 4, n. 1, p. 1-27, 2016.

BESSIÈRE, J. Local development and heritage: traditional food and cuisine as tourist attractions in rural areas. Sociologia Ruralis, Assen, v. 38, n. 1, p. 21-34, Apr. 1998.

BLUME, R. Explorando os recursos estratégicos do terroir para a vitivinicultura brasileira. 2008. $360 \mathrm{f}$. Tese (Doutorado em Agronegócio) - Universidade Federal do Rio Grande do Sul, Porto Alegre, 2008.

BRANCO, N. P. N. C. de S. et al. Indicações geográficas (IGs) como ferramenta para desenvolvimento regional: uma prospecção tecnológica sobre IGs relacionadas à farinha e mandioca; e o potencial da IG da farinha de mandioca Copioba do Recôncavo Baiano. In: SIMPÓSIO INTERNACIONAL DE INOVAÇÃO TECNOLÓGICA, 1., 2013, Aracaju. Anais... Aracaju: SIMTEC, 2013. p. 771-786. 
BRANDÃO, B. O. A valorização dos produtos tradicionais através da indicação geográfica: o potencial do Aratu de Santa Luzia do Itanhy. 2016. 75 f. Dissertação (Mestrado em Ciência da Propriedade Intelectual) Universidade Federal de Sergipe, São Cristóvão, 2016.

BRANDÃO, F. Percepções do consumidor de carne com indicações geográficas. 2009. 77 f. Dissertação (Mestrado em Agronegócios) - Universidade Federal do Rio Grande do Sul, Porto Alegre, 2009.

CERDAN, C.; VITROLLES, D. Valorisation des produits d'origine : contribution pour penser le développement durable dans la Pampa Gaúcha au Brésil. Géocarrefour, Lyon, v. 83, n. 3, p. 191-200, 2008.

COLLINS, J. L. The pineapple: botany, cultivation and utilization. New York: Interscience Publishers, 1960. 294 p.

CONFEDERAÇÃO NACIONAL DA AGRICULTURA - CNA. Consumo de frutas e hortaliças: pesquisa quantitativa. Connection Research, Pinheiros, p. 1-50, May 2011.

CRESTANI, M. et al. Das Américas para o mundo: origem, domesticação e dispersão do abacaxizeiro. Ciência Rural, Santa Maria, v. 40, n. 6, p. 1473-1483, jun. 2010.

CUNHA, G. A. P. Equipe técnica de abacaxi comemora 30 anos de atividades e realizações. Cruz das Almas: Embrapa Mandioca e Fruticultura Tropical, 2007. 20 p.

DALLABRIDA, V. R. (Org.). Território, identidade territorial e desenvolvimento regional: reflexões sobre indicação geográfica e novas possibilidades de desenvolvimento com base em ativos com especificidade territorial. São Paulo: Editora LiberArs, 2013. 236 p.

FALCÃO, T. F.; RÉVILLION, J. P. A indicação geográfica de vinhos finos segundo a percepção de qualidade de enófilos. Ciência Rural, Santa Maria, v. 40, n. 2, p. 453458, fev. 2010.

FAVARETO, A. A expansão produtiva em regiões rurais há um dilema entre crescimento econômico, coesão social e conservação ambiental? In: GASQUES, J. G.; VIEIRA FILHO, J. E. R.; NAVARRO, Z. (Org.). A agricultura brasileira: desempenho, desafios e perspectivas. Brasília: IPEA, 2010. p. 213-235.
FERREIRA, F. R.; CABRAL, J. R. S. Pineapple germplasm in Brazil. Acta Horticulturae, The Hague, v. 334, p. 23-26, 1993.

FONTE, M. Knowledge, food and place: a way of producing, a way of knowing. Sociologia Ruralis, Assen, v. 48 , n. 3, p. 200-222, June 2008.

FOOD AND AGRICULTURE ORGANIZATION OF THE UNITED NATIONS STATISTICAL DATABASE FAOSTAT. Crops database. FAO, Italy, 2010. Disponível em: <http://faostat.fao.org/site/567/DesktopDefault. aspx?PageID=567\#ancor $>$. Acesso em: 20 mar. 2012.

GIL, A. C. Como elaborar projetos de pesquisa. 4. ed. São Paulo: Atlas, 2002. 175 p.

GLASS, R. F.; CASTRO, A. M. G. As indicações geográficas como estratégia mercadológica no mercado de vinhos do Distrito Federal. Organizações Rurais \& Agroindustriais, Lavras, v. 10, n. 2, p. 189-202, 2008.

HINRICHS, C. C. Embeddedness and local food systems: notes on two types of direct agricultural market. Journal of Rural Studies, New York, v. 16, n. 3, p. 295-303, July 2000.

HOLT, G.; AMILIEN, V. Introduction: from local food to localised food. Anthropology of Food, France, n. S2, Mar. 2007. Disponível em: $<$ http://aof.revues.org/document 405 . html >. Acesso em: 10 mar. 2016.

INSTITUTO BRASILEIRO DE GEOGRAFIA E ESTATÍSTICA - IBGE. Banco de dados agregados. [S.1.]: IBGE, 2012. Disponível em: <http://www.sidra.ibge.gov. br>. Acesso em: 22 mar. 2012.

LANCASTER, K. J. A new approach to consumer theory. The Journal of Political Theory, Chicago, v. 74, n. 2, p. 132-157, Apr. 1966.

. Modern consumer theory. London: Edward Elgar Publishing Limited, 1991. 256 p.

LEMOS, A. R. Análise da comunicação de marketing no varejo de alimentos na cidade de São Paulo. 2011. 193 f. Dissertação (Mestrado em Nutrição Humana Aplicada) - Universidade de São Paulo, São Paulo, 2011. 
LIMA FILHO, D. O. et al. Decisão de compra das classes a/b em supermercados. Revista Cesumar Ciências Humanas e Sociais Aplicadas, Maringá, v. 18, n. 2, p. 353-374, jul./dez. 2013.

MAIORKI, G. J.; DALLABRIDA, V. R. A indicação geográfica de produtos: um estudo sobre sua contribuição econômica no desenvolvimento territorial. Interações, Campo Grande, v. 16, n. 1, p. 13-25, jan./jun. 2015.

MALHOTRA, N. K. Pesquisa em marketing: uma orientação aplicada. 3. ed. Porto Alegre: Bookman, 2001. 719 p.

MARSDEN, T.; BANKS, J.; BRISTROW, G. Food supply chain approaches: exploring their role in rural development. Sociologia Ruralis, Assen, v. 40, n. 4, p. 424-438, Oct. 2000.

MATOS, L. A. I. O conhecimento regional do queijo Minas artesanal na indicação de procedência Canastra: ensinando o padre a rezar. 2016. 247 f. Tese (Doutorado em Políticas Públicas, Estratégias e Desenvolvimento) Universidade Federal do Rio de Janeiro, Rio de Janeiro, 2016.

MATOS, L. I.; LA ROVERE, R. L. As diferentes interpretações dos conceitos de indicações geográficas por instituições brasileiras. Desenvolvimento Regional em Debate, Contestado, v. 7, n. 1, p. 4-24, maio 2017.

MORAES, A. S. et al. Percepções de consumidores sobre carne bovina com indicação geográfica de raças locais brasileiras, Campo Grande - MS. In: SIMPÓSIO SOBRE RECURSOS NATURAIS E SOCIOECONÔMICOS DO PANTANAL, 6., 2013, Corumbá. Anais... Corumbá: Embrapa Pantanal, 2013. p. 1-6.

MOURA, T. L.; SILVA, A. L.; BATALHA, M. O. Perfil dos consumidores que freqüentam os formatos de varejo de alimentos no Brasil. In: ENCONTRO NACIONAL DE PROGRAMAS DE PÓS-GRADUAÇÃO E PESQUISA EM ADMINISTRAÇÃ, 30., 2006, Salvador. Anais Eletrônicos... Salvador: ANPAD, 2006. p. 1-15.

MUCHNIK, J. Sistemas agroalimentarios localizados: evolución del concepto y diversidad de situaciones. In: CONGRESO INTERNACIONAL DE LA RED SIAL ALIMENTATION Y TERRITORIOS, 3., 2006, Baeza. Anais... Baeza: Universidad Internacional de Andalucía, 2006. p. 1-21.
MURDOCH, J.; MIELE, M. Back to nature: changing worlds of production in the food sector. Sociologia Ruralis, Assen, v. 39, n. 4, p. 465-483, Oct. 1999.

NIEDERLE, P. A. Compromissos para a qualidade: projetos de indicação geográfica para vinhos no Brasil e na França. 2011. 263 f. Tese (Doutorado em Ciências Sociais) - Universidade Federal Rural do Rio de Janeiro, Rio de Janeiro, 2011.

PARROT, N.; WILSON, N.; MURDOCH, J. Spatializing quality: regional protection and the alternative geography of food. European Urban and Regional Studies, Harlow, v. 9, n. 3, p. 241-261, July 2002.

PECQUEUR, B. Territoire, territorialité et développement. In: COLLOQUE INDUSTRIE ET TERRITOIRE: LES SYSTÈMES PRODUCTIFS LOCALISÉS, 1992, Grenoble. Anais... Grenoble: IREP-D, 1992. 1 CD-ROM.

PELLIN, V.; RIBEIRO, J. C.; MANTOVANELI JÚNIOR, O. Contribuições dos produtos tradicionais para o território: experiência do queijo Serra da Estrela em Portugal. Revista Territórios e Fronteiras, Cuiabá, v. 9, n. 1, p. 264-284, jan./jun. 2016.

REARDON, T. The global rise and impact of supermarkets: an international perspective. In: CONFERENCE THE SUPERMARKET REVOLUTION IN FOOD: GOOD, BAD OR UGLY FOR THE WORLD'S FARMERS, CONSUMERS AND RETAILERS, 2011, Canberra. Anais Eletrônicos... Canberra: Crawford Fund for International Agricultural Research, Parliament House, 2011. p. 1-29. 1 CD-ROM.

REARDON, T.; BERDEGUÉ, J. A. The rapid rise of supermarkets in Latin America. Development Policy Review, London, v. 20, n. 4, p. 371-388, Sept. 2002.

ROCHA, E. L. Propriedade intelectual por indicação geográfica: o caso da cachaça do Brejo paraibano. 2016. 132 f. Dissertação (Mestrado em Administração) - Universidade Federal da Paraíba, João Pessoal, 2016.

ROOS, G.; TERRAGNI, L.; TORJUSEN, H. The local in the global: creating ethical relations between producers and consumers. Anthropology of Food, France, n. S2, Mar. 2007. Disponível em: $<$ http://aof.revues.org/document 489 . html >. Acesso em: 10 mar. 2016. 
SACHET, M. A. Territory, geographical indication and territorial development. Desenvolvimento Regional em Debate, Contestado, v. 6, n. 1, p. 4-21, jan./jul. 2016.

SANTIN, A.; PINHEIRO, M. F. M. A cultura do abacaxizeiro no Litoral Norte do RS: histórico, problemas e perspectivas. Letras da Terra, Osasco, n. 20, 2009. Disponível em: <http:// www.agptea.org.br/imagem/pdf/ LT20FINAL.pdf $>$. Acesso em: 10 mar. 2015.

SANTOS, J. S. Dilemas e desafios na valorização de produtos alimentares tradicionais no Brasil: um estudo a partir do Queijo do Serro, em Minas Gerais, e do Queijo Serrano, no Rio Grande do Sul. 2014. 260 f. Tese (Doutorado em Agronomia) - Universidade Federal de Pelotas, Pelotas, 2014.

SIRIEX, L. Définition et utilisation des concepts de valeurs et buts pour la recherche en marketing. In: PRAS, B. (Coord.). Faire de la recherche en marketing? Paris: Librairie Vuibert, 1999. Cap. 3, p. 98-112.
SONINO, R.; MARSDEN, T. Beyond the divide: rethinking relationships between alternative and conventional food networks in Europe. Journal of Economic Geography, Essex, v. 6, n. 2, p. 181-199, Apr. 2006.

SOUZA, R. S. et al. Comportamento de compra dos consumidores de frutas, legumes e verduras na região central do Rio Grande do Sul. Ciência Rural, Santa Maria, v. 38 , n. 2, p. 511-517, mar./abr. 2008.

VALCESCHINI, E. La dénomination d'origine comme signal de qualité crédible. Revue d'Economie Régionale et Urbaine, Paris, n. 3, p. 489-500, 2000.

VALENTE, M. E. R. et al. Indicação geográfica de alimentos e bebidas no Brasil e na União Europeia. Ciência Rural, Santa Maria, v. 42, n. 3, p. 551-558, mar. 2012.

VIALTA, A. et al. Brasil food trens 2020. São Paulo: Ideal, 2010. $173 \mathrm{p}$. 